\title{
The publication trends and hot spots of scoliosis research from 2009 to 2018: a 10-year bibliometric analysis
}

\author{
Lin Tao", Siming Zhou", Zhengbo Tao", Kaicheng Wen, Wacili Da, Yan Meng, Yue Zhu \\ Department of Orthopaedics, The First Hospital of China Medical University, Shenyang 110001, China \\ Contributions: (I) Conception and design: L Tao, Y Zhu; (II) Administrative support: Y Zhu; (III) Provision of study materials or patients: Y Zhu; \\ (IV) Collection and assembly of data: L Tao, S Zhou, Z Tao; (V) Data analysis and interpretation: S Zhou, Z Tao, K Wen, W Da, Y Meng; (VI) \\ Manuscript writing: All authors; (VII) Final approval of manuscript: All authors. \\ \#These authors contributed equally to this work. \\ Correspondence to: Yue Zhu. 155 Nan Jing North Street, Shenyang 110001, China. Email: zhuyuedr@163.com.
}

\begin{abstract}
Background: This study aims to quantitatively and qualitatively investigate the trends in scoliosis research and evaluate research hotspots using bibliometric analysis.

Methods: All relevant publications on scoliosis from the period from 2009 to 2018 were extracted from the Web of Science and PubMed databases. Publication trends were analyzed using an Online analysis platform of literature metrology, Bibliographic Item Co-occurrence Matrix Builder (BICOMB), and CiteSpace software. Hotspots were analyzed and visualized using the gCLUTO software package.

Results: A total of 7,445 scoliosis research publications dated between 2009 and 2018 were found. The spine was the most popular journal in this field during this period. The United States maintained a top position in global scoliosis research throughout the 10 years and has had a pivotal influence, followed by China and Canada. Among all institutions, the University of California, San Francisco, was a leader in research collaboration. At the same time, Professors Yong Qiu and Lawrence G. Lenke made great achievements in scoliosis research. We analyzed the major Medical Subject Headings (MeSH) terms/MeSH subheadings and identified eight hotspots in scoliosis research.

Conclusions: We summarized the publication information of scoliosis-related literature in the 10 years from 2009 to 2018, including country and institution of origin, authors, and publication journal. We analyzed former research hotspots in the field of scoliosis and predicted future areas of interest. The development of various new orthopedic plants, artificial intelligence diagnosis, and genetic research will be future hotspots in scoliosis research.
\end{abstract}

Keywords: Scoliosis; bibliometric analysis; hotspots; co-word biclustering analysis

Submitted Jan 04, 2020. Accepted for publication Feb 03, 2020.

doi: $10.21037 /$ atm.2020.02.67

View this article at: http://dx.doi.org/10.21037/atm.2020.02.67

\section{Introduction}

Scoliosis is a three-dimensional (3D) structural spinal deformity and usually manifests as raised ribs, unlevel shoulders, and an asymmetrical waist. It can be diagnosed through a posteroanterior spinal radiograph taken in a standing position which shows a lateral bending of the spine over $10^{\circ}$. In addition to a curved spine, scoliosis is often related to the asymmetry of the trunk and limbs (1). Congenital, neurogenic, and some other classifications of scoliosis have better understood underlying mechanisms compared to idiopathic scoliosis, which denotes a curve of unknown etiology. Idiopathic scoliosis accounts for about $80 \%$ of structural coronal deformities (2), and the diagnosis rules out a pre-existing cause. With the continuous improvements in medicine and quality of life, scoliosis has attracted more and more attention. However, many problems relating to clinical treatment and scientific research still need to be solved. According to recent 
research hotspots combined with practical clinical problems, surgeons and researchers also need to improve the quality of scoliosis diagnosis and treatment, so as to alleviate the pain patients experience during treatment.

In recent years, bibliometric analysis has become increasingly popular. It applies literature metrology characteristics to measure the contribution of an area of research, including disparate countries, institutions, journals, or authors and predicts in detail research trends or hot spots within a certain field. However, there have been few bibliometric studies on scoliosis, and these mainly focus on published information rather than analysis and prediction of research hotspots $(3,4)$. Our previous study showed that biclustering analysis could facilitate the discovery of key research focus areas and related representative literature (5). In particular, co-word biclustering analysis can be used to verify hot spots in research. In this article, we apply an integrated analysis of the content and external features of research literature to identify hot spots in scoliosis pathology, surgical method innovation and implants, quality of life after brace treatment, adverse effects, and diagnostic imaging, as well as genetics. We conduct a brief discussion on scoliosis research and clinical issues and make a prediction on possible progress in the field over the next decade.

\section{Methods}

\section{Data sources and search strategies}

We considered the Science Citation Index-Expanded and the Social Science Citation Index of Thomson Reuters' Web of Science to be the most appropriate databases on which to perform our bibliometric analysis. We comprehensively searched Web of Science database to find relevant data from 2009 to 2018 and only included original articles and reviews. The search strategy was presented as follows: $\mathrm{TI}=$ (scoliosis) AND Language $=$ English. At the same time, to obtain the Medical Subject Headings (MeSH) terms information which can map the contents of literature and be used to carry out co-word clustering analysis (6), we performed a similar online search on PubMed, which was developed by the National Center for Biotechnology Information (NCBI) of National Library of Medicine (NLM), without language restrictions. The search term used was "scoliosis"[Mesh] from 2009 to 2018. To avoid bias incurred by frequent database renewal, all literature retrieval and data downloads were completed in a single day, September 26, 2019.

\section{Data collection}

Two reviewers ( $Z$ Tao and S Zhou) independently performed the primary search, and their agreement rate reached 0.90, showing significant accordance (7). Web of Science Core Collection (WoSCC) data including titles, countries of origin, institutions, journals, and authors, were extracted and imported into the Online Analysis Platform of Bibliometrics (http://bibliometric.com/) and CiteSpace V5.5.R1 SE, 64bit (Drexel University, Philadelphia, PA, USA) for bibliometric analysis. PubMed data were imported into the BICOMB (Bibliographic Item Co-Occurrence Matrix Builder) (8) for further hot spot analysis.

\section{Bibliometric analysis}

We attempted to describe all publication characteristics, including countries, institutions, journals, authors, and $\mathrm{H}$ index. We accessed the 2018 version of Journal Citation Reports (JCR) to obtain the impact factor (IF), which is regarded as an important indicator to measure the scientific value of research (9). In our study, we analyzed the annual publication numbers and growth tendencies of different countries/regions through the Literature Metrology online analysis platform. CiteSpace is an optimal means for collaboration network analysis to connect all kinds of publication characteristics. It can also obtain keywords with high citations to predict the research frontiers and emerging trends in this area. Through CiteSpace, a "time slicing" function can also be applied (e.g., if you set the "years per slice" to 1 while the "top $\mathrm{N}$ per slice" is set to 50 , the top 50 papers in a year are exported into a single file). According to our objective, nodes of different sizes represented citation counts or publication counts $(10,11)$.

\section{Co-word biclustering analysis of research hotspots}

Biclustering was used to display the connection between extremely frequent terms and source literature, and the connection among extremely frequent terms. To survey the hotspots of scoliosis study, we performed a biclustering analysis of the incorporated publications and major $\mathrm{MeSH}$ terms/MeSH subheadings. BICOMB is a binary matrix that has source literature as columns and major $\mathrm{MeSH}$ terms/MeSH subheadings as rows, and structured through software "gCLUTO" version 1.0 (12). The detailed 


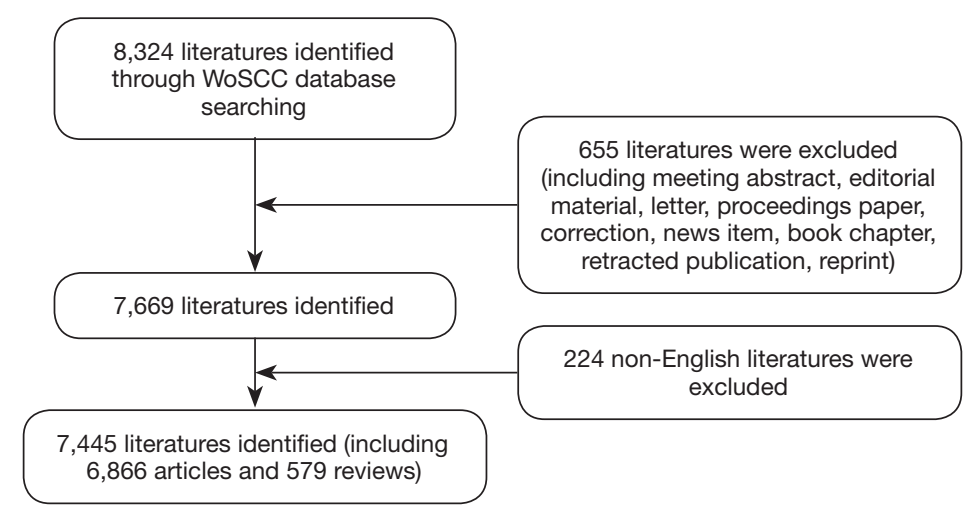

Figure 1 Flow chart of literature filtering included in this study. WoSCC, Web of Science Core Collection.

principle is explained in our previous research (5). We found semantic relationships between major $\mathrm{MeSH}$ terms/MeSH subheadings and source literature in clusters of scoliosis research focus and mapped them by matrix and mountain visualization.

\section{Results}

\section{The output of related literature}

A total of 7,445 publications (6,866 articles and 579 reviews) from 2009 to 2018 met our inclusion criteria (Figure 1). Figure $2 A$ shows the increasing trend in the numbers of scoliosisrelated publications (from 481 in 2009 to 966 in 2018).

\section{The contributions of countries and institutions to global publications}

The incorporated literature on scoliosis was contributed by at least 84 different countries or regions (Figure 2B). The United States $[2,818]$ was the largest contributor to scoliosis research, followed by China [1,281], Canada [561], Japan [529], and France [444]. Centrality is a major indicators to determine the importance of nodes in the network and a higher centrality means that the node is more important in this network, so the results showed that the United States had more impact than any other country (centrality $=0.22)$, and then England (0.16), and Germany (0.14) (Table 1). In terms of research institutions, the top 10 included the University of California, San Francisco [347], Nanjing University [301], Washington University [297], Chinese University of Hong Kong [263], and New York University [234] (Table 1). A low-density map of the scoliosis research network (density $=0.0642)$ (Figure $3 A$ ) means that the research teams were relatively scattered across various institutions, and more mutual cooperation is needed. Most of the central indexes are below 0.15 , indicating that most institutions had a low level of impact and that there was insufficient cooperation during the 10-year period. International cooperation analysis showed that cooperation happened most frequently between the United States and Canada, followed by the United States and China (Figure 3B).

\section{Journals publishing researches on scoliosis}

Recently, 1,056 journals have appeared in the field of scoliosis research. The top 10 most popular journals published 3,308 of all 7,445 pieces of literature on scoliosis in our study (44.43\%) (Table 2). Of these, the top 3 journals are Spine, European Spine Fournal, and Spine Fournal, which accounted for more than $30.50 \%$ of all the indexed publications. The highest IF belonged to The Fournal of Bone and Foint Surgery-American Volume (4.716), followed by Spine Fournal (3.196), Journal of Neurosurgery-Spine (2.998), Spine (2.903), and European Spine fournal (2.513). According to the JCR 2018 standards, the five journals mentioned above are classified as Q1, the Fournal of Pediatric Orthopaedics, World Neurosurgery, and Clinical Spine Surgery are classified as Q2, and the American Fournal of Medical Genetics Part A is classified as Q3.

\section{The contributions of authors to scoliosis research}

The ten authors who published the most papers out of all 22,511 authors in this study are listed in Table 3. Of these, Yong Qiu, from the Department of Spine Surgery, 

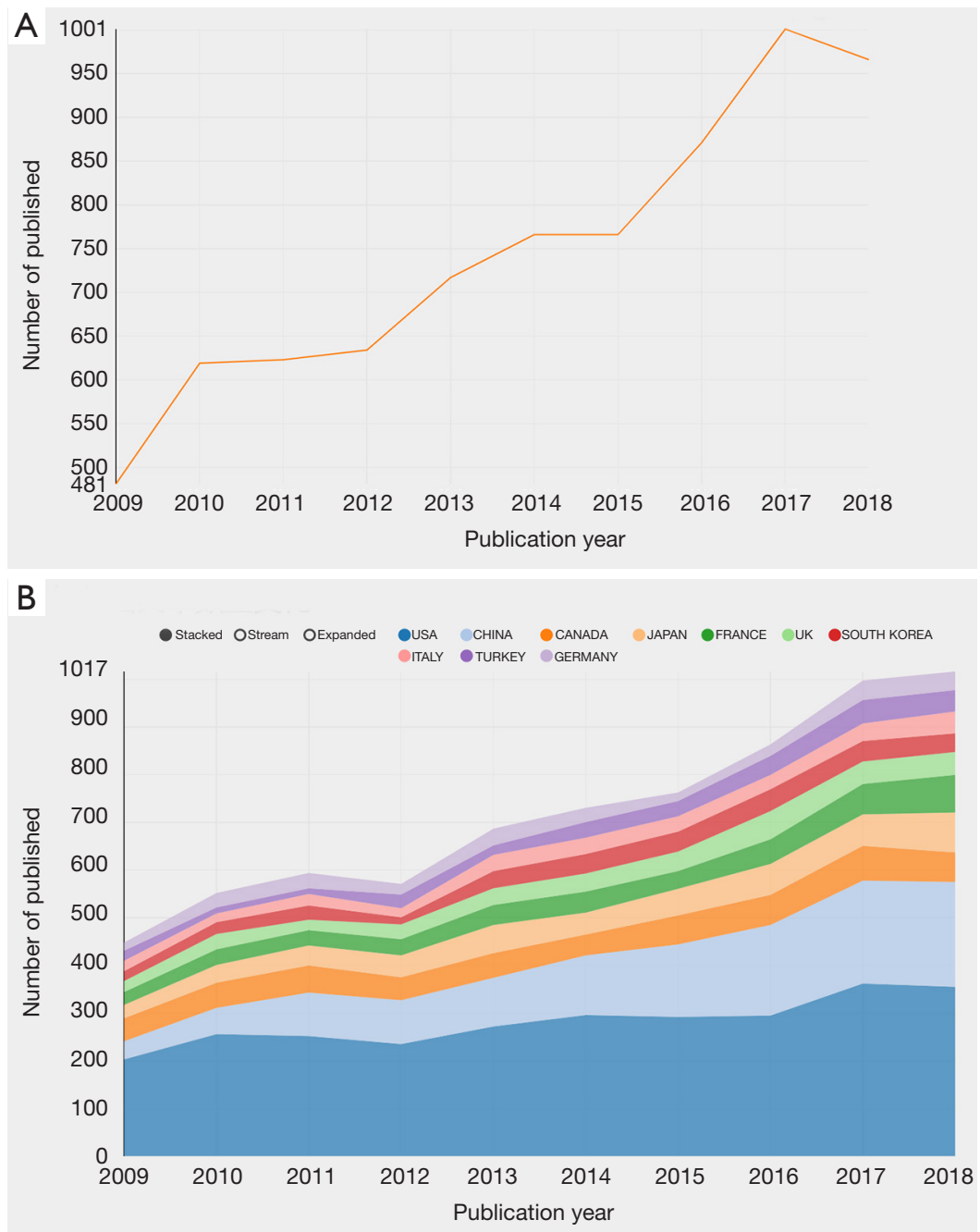

Figure 2 Output of related literature. The number of annual publications (A) and growth trends of the top 10 countries/regions (B) in scoliosis research from 2009 to 2018 .

Nanjing Drum Tower Hospital in China, ranked first [221], and second was Virginie Lafage from the Department of Orthopaedic Surgery, Hospital for Special Surgery in the USA [178]. These two scholars made great achievements and have become authorities in scoliosis research. We analyzed the citation information for authors (Figure $4 A$ ) and co-cited authors (Figure $4 B$ ), visualizing them in a network by CiteSpace. Lawrence G. Lenke (899 cocitations) ranked first in the top 10 co-cited authors, followed by Young-Jo Kim [786], Keith H. Bridwell [661], and Si Suk [647] (Table 3). The centrality of the top 4 is more than 0.1 , demonstrating that they have become an influential core group in the scoliosis field, having carried out a lot of research to lay a better foundation for future development. And the analysis of high-cited papers showed Virginie Lafage group have an amazing scientific impact for other scholars, 4 of top 10 high-cited papers were published by this group (Table 4).

\section{Analysis of the scoliosis hotspots}

Based on the search results, there were 4,857 major MeSH terms/MeSH subheadings with a cumulative frequency of 24,055 times. They can be defined as extremely frequent terms that appeared more than 52 times after a standard evaluation of $\mathrm{H}$-index, and their frequency accounted for $46.78 \%(11,252 / 24,055)$ of all (Table 5$)$. We analyzed the temporal trend of hotspot shift according to the 
Table 1 The top 10 countries/regions and institutions contributing to publications in scoliosis research

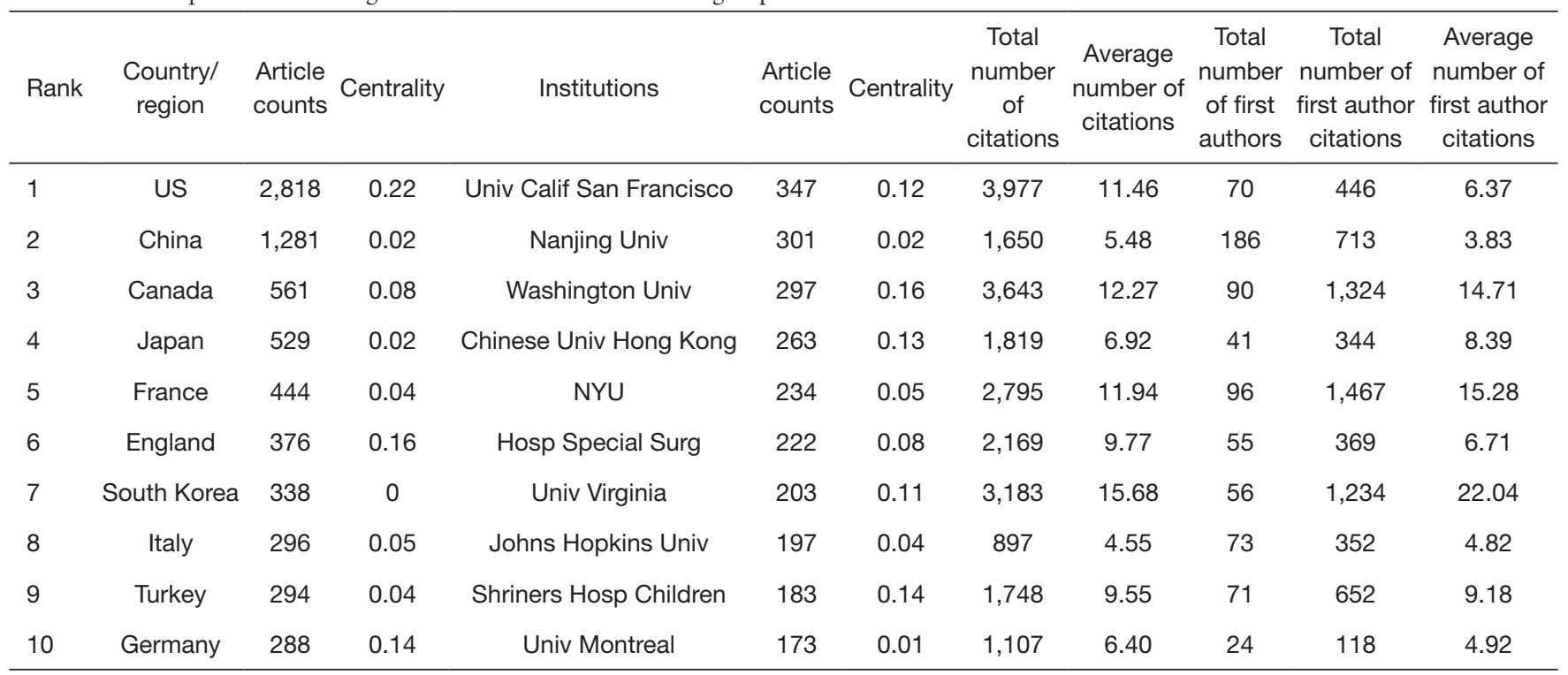

A

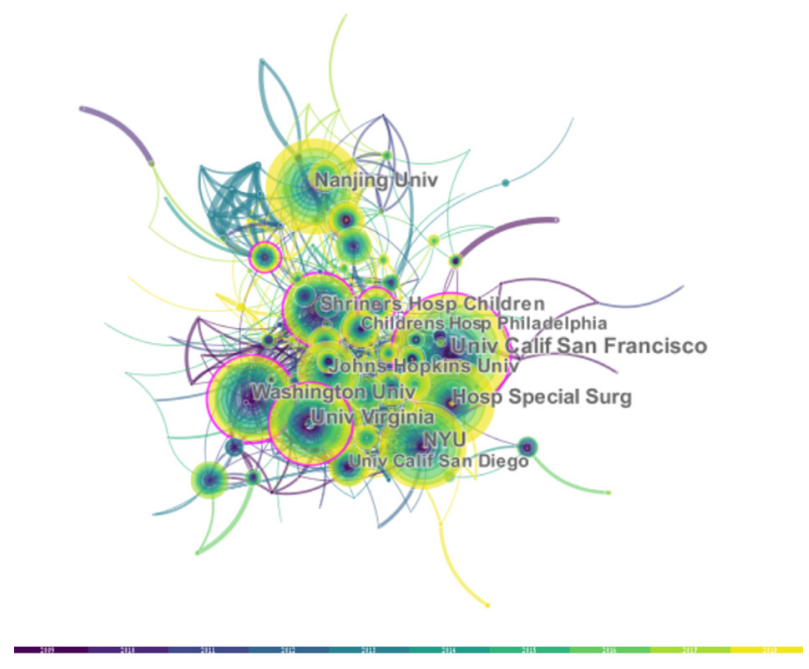

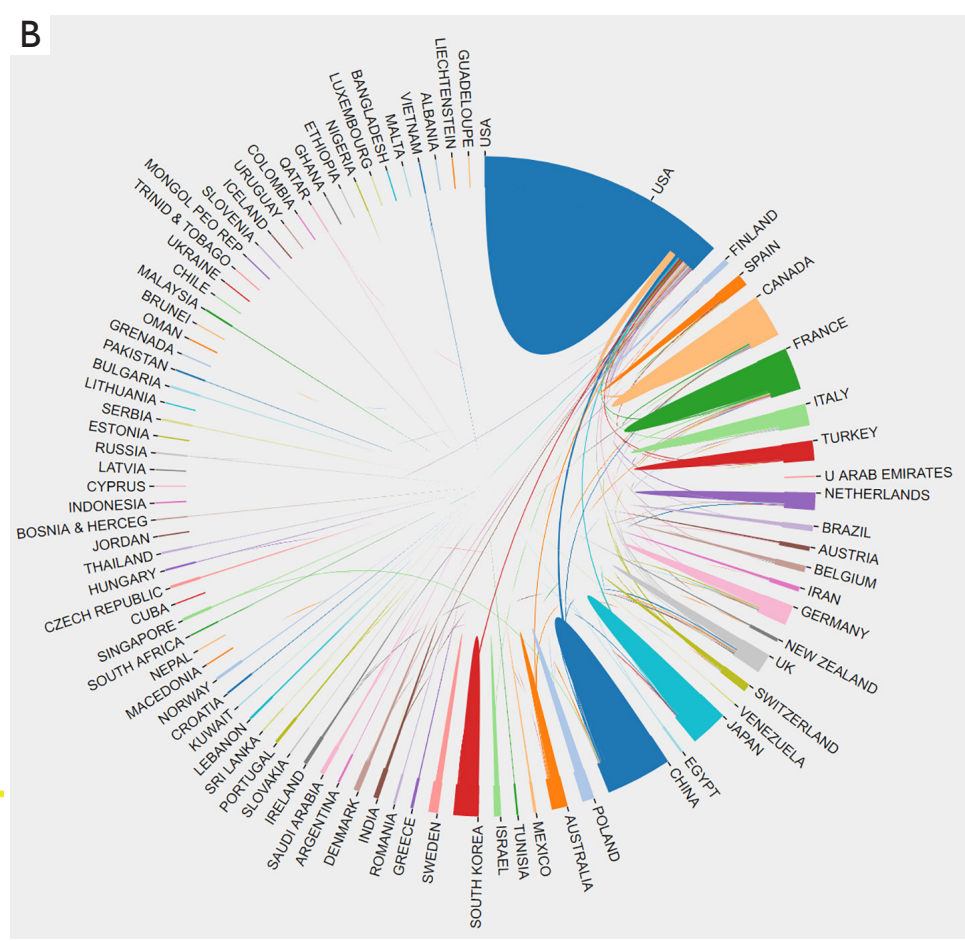

Figure 3 The distribution of countries/regions and institutions. The network map of institutions involved in scoliosis research (A) and cooperation between countries/regions (B). 
Table 2 The top 10 most active journals that published articles in scoliosis research (sorted by count)

\begin{tabular}{|c|c|c|c|c|c|c|c|c|}
\hline Rank & Journal title & $\begin{array}{c}\text { Percentage } \\
(\mathrm{N} / 7,445)\end{array}$ & IF (2018) & $\begin{array}{c}\text { Quartile in } \\
\text { category } \\
(2018)\end{array}$ & H-index & $\begin{array}{l}\text { Article } \\
\text { counts }\end{array}$ & $\begin{array}{c}\text { Total number } \\
\text { of citations }\end{array}$ & $\begin{array}{l}\text { Average } \\
\text { number of } \\
\text { citations }\end{array}$ \\
\hline 2 & European Spine Journal & $10.44 \%$ & 2.513 & Q1 & 117 & 777 & 4,623 & 5.95 \\
\hline 3 & Spine Journal & $4.15 \%$ & 3.196 & Q1 & 94 & 309 & 1,123 & 3.63 \\
\hline 5 & Journal of Neurosurgery-Spine & $2.81 \%$ & 2.998 & Q1 & 84 & 209 & 1,305 & 6.24 \\
\hline 6 & Journal of Spinal Disorders \& Techniques & $1.84 \%$ & 0 & 0 & 85 & 137 & 805 & 5.88 \\
\hline 7 & Journal of Bone and Joint Surgery-American Volume & $1.48 \%$ & 4.716 & Q1 & 235 & 110 & 872 & 7.93 \\
\hline 8 & World Neurosurgery & $1.38 \%$ & 1.723 & Q2 & 85 & 103 & 39 & 0.38 \\
\hline
\end{tabular}

Table 3 The top 10 most productive authors and co-cited authors contributed to publications in scoliosis research

\begin{tabular}{|c|c|c|c|c|c|c|c|c|c|c|c|c|c|}
\hline Rank & Author & $\begin{array}{l}\text { Article } \\
\text { counts }\end{array}$ & Centrality & $\begin{array}{c}\text { Total } \\
\text { number } \\
\text { of } \\
\text { citations }\end{array}$ & $\begin{array}{l}\text { Average } \\
\text { number } \\
\text { of } \\
\text { citations }\end{array}$ & $\begin{array}{l}\text { First } \\
\text { author } \\
\text { counts }\end{array}$ & $\begin{array}{l}\text { First } \\
\text { author } \\
\text { citation } \\
\text { counts }\end{array}$ & $\begin{array}{l}\text { Average } \\
\text { first } \\
\text { author } \\
\text { citation } \\
\text { counts }\end{array}$ & $\begin{array}{l}\text { Corresponding } \\
\text { author }\end{array}$ & $\begin{array}{l}\text { Corresponding } \\
\text { author citation } \\
\text { counts }\end{array}$ & $\begin{array}{l}\text { Co-cited } \\
\text { author }\end{array}$ & $\begin{array}{l}\text { Citation } \\
\text { counts }\end{array}$ & Centrality \\
\hline 1 & Qiu Y & 221 & 0.04 & 1,086 & 4.91 & 5 & 63 & 12.60 & 101 & 582 & Lenke LG & 899 & 0.22 \\
\hline 4 & Smith JS & 150 & 0.08 & 2,169 & 14.46 & 22 & 802 & 36.45 & 32 & 529 & Suk Si & 647 & 0.10 \\
\hline 5 & $\begin{array}{c}\text { Shaffrey } \\
\mathrm{Cl}\end{array}$ & 144 & 0.10 & 2,255 & 15.66 & 0 & 0 & 0 & 15 & 670 & $\begin{array}{c}\text { Weinstein } \\
\text { SL }\end{array}$ & 636 & 0.07 \\
\hline 8 & Ames CP & 118 & 0.04 & 1,386 & 11.75 & 2 & 42 & 21.00 & 12 & 106 & $\begin{array}{l}\text { Lonstein } \\
\text { JE }\end{array}$ & 489 & 0.08 \\
\hline 9 & Schwab F & 118 & 0.09 & 2,236 & 18.95 & 4 & 489 & 122.25 & 2 & 161 & Kuklo TR & 429 & 0.05 \\
\hline 10 & Liu Z & 109 & 0.14 & 435 & 3.99 & 7 & 54 & 7.71 & 2 & 0 & Smith JS & 422 & 0.04 \\
\hline
\end{tabular}

top 25 terms with the strongest citation bursts during 2009 to 2018 (Figure 5). And we sorted eight different clusters by biclustering, mapping the connection between source literature and $\mathrm{MeSH}$ terms/MeSH subheadings by mountain and matrix visualization (Figure 6). The biclustering result can visually show the substance of highdimensional datasets through mountain visualization. There are 8 perks representing 8 clusters in the $3 \mathrm{D}$ landform numbered from 0 to 7 (Figure 6). The information of these clusters is reflected by the perks' volume, altitude, color 
A



B

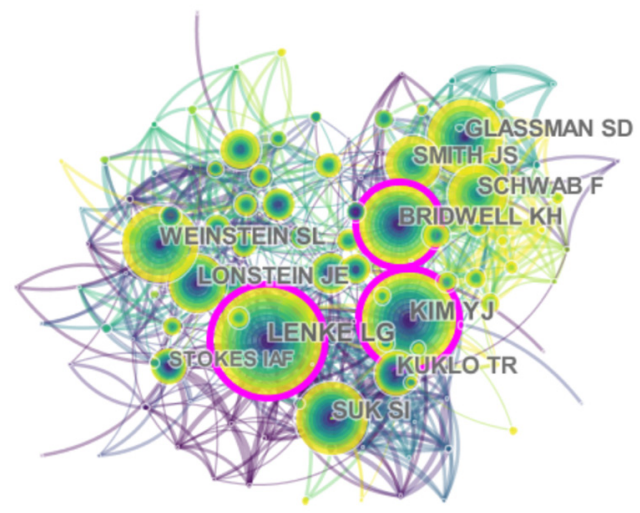

Figure 4 The distribution of authors engaged in scoliosis research. The network map of productive authors (A) and the network map of cocited authors (B).

Table 4 The top 10 high-cited papers in scoliosis research during 2009 to 2018

\begin{tabular}{|c|c|c|c|c|c|}
\hline Rank & Title & Journal & $\begin{array}{l}\text { Corresponding } \\
\text { authors }\end{array}$ & $\begin{array}{l}\text { Publication } \\
\text { year }\end{array}$ & $\begin{array}{c}\text { Total } \\
\text { citations }\end{array}$ \\
\hline 1 & Prader-Willi syndrome & Genetics in Medicine & Cassidy SB & 2012 & 465 \\
\hline 3 & $\begin{array}{l}\text { Adult spinal deformity-postoperative standing imbalance: how } \\
\text { much can you tolerate? An overview of key parameters in assessing } \\
\text { alignment and planning corrective surgery }\end{array}$ & Spine & Lafage V & 2010 & 373 \\
\hline 4 & $\begin{array}{l}\text { Scoliosis Research Society-Schwab Adult Spinal Deformity } \\
\text { Classification: a validation study }\end{array}$ & Spine & Lafage V & 2012 & 334 \\
\hline 5 & Effects of bracing in adolescents with idiopathic scoliosis & $\begin{array}{l}\text { New England Journal } \\
\text { of Medicine }\end{array}$ & Weinstein SL & 2013 & 310 \\
\hline 8 & $\begin{array}{l}\text { Accuracy of pedicle screw placement: a systematic review of } \\
\text { prospective in vivo studies comparing free hand, fluoroscopy } \\
\text { guidance and navigation techniques }\end{array}$ & $\begin{array}{l}\text { European Spine } \\
\text { Journal }\end{array}$ & Gelalis ID & 2012 & 226 \\
\hline 9 & $\begin{array}{l}\text { Complications of growing-rod treatment for early-onset scoliosis: } \\
\text { analysis of one hundred and forty patients }\end{array}$ & $\begin{array}{l}\text { Journal of Bone and } \\
\text { Joint Surgery-American } \\
\text { Volume }\end{array}$ & Akbarnia B & 2010 & 210 \\
\hline 10 & Postural deformities in Parkinson's disease & Lancet Neurology & Bloem BR & 2011 & 208 \\
\hline
\end{tabular}


Page 8 of 15

Tao et al. A scoliosis research bibliometric analysis

Table 5 Highly frequent major MeSH terms from the included publications on scoliosis $(n=24,055)$

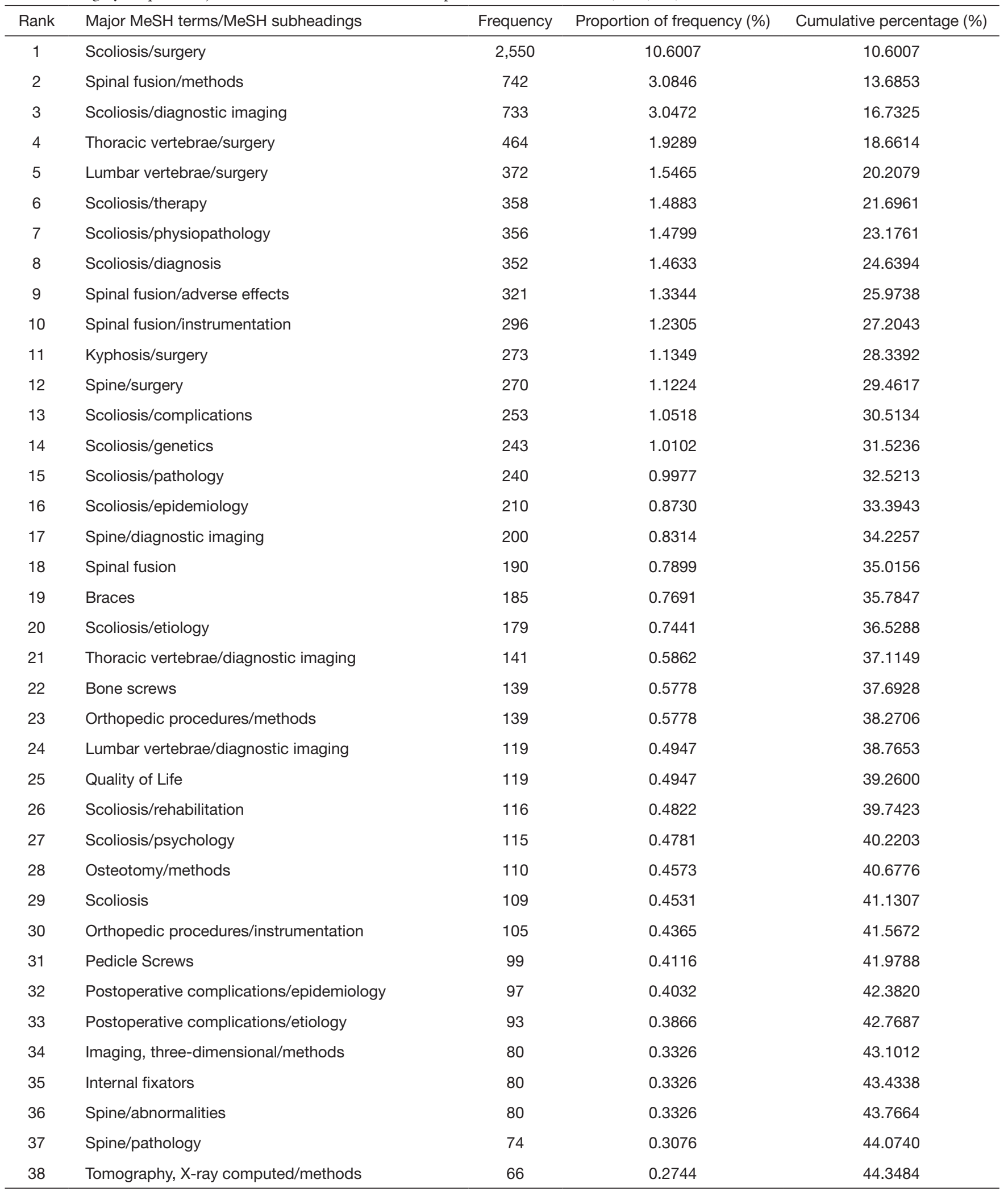

Table 5 (continued) 
Table 5 (continued)

\begin{tabular}{clccc}
\hline Rank & Major MeSH terms/MeSH subheadings & Frequency & Proportion of frequency (\%) & Cumulative percentage (\%) \\
\hline 39 & Orthopedic procedures/adverse effects & 64 & 0.2661 & 44.6144 \\
40 & Ribs/surgery & 64 & 0.2661 & 44.8805 \\
41 & Prostheses and Implants & 62 & 0.2577 & 45.1382 \\
42 & Kyphosis/diagnostic imaging & 60 & 0.2494 & 45.3877 \\
43 & Postural balance/physiology & 59 & 0.2453 & 45.6329 \\
44 & Posture & 59 & 0.2453 & 45.8782 \\
45 & Scoliosis/congenital & 56 & 0.2328 & 46.1110 \\
46 & Cerebral palsy/complications & 54 & 0.2245 & 46.3355 \\
47 & Scoliosis/classification & 54 & 0.2245 & 46.5600 \\
48 & Genetic predisposition to disease & 52 & 0.2162 & 46.7761 \\
\hline
\end{tabular}

MeSH, Medical Subject Headings.

\begin{tabular}{|c|c|c|c|c|c|}
\hline MeSH terms/ MeSH subheadings & Year & Strength & Begin & End & $2009-2018$ \\
\hline cotrel dubousset instrumentation & 2009 & 14.4844 & 2009 & 2012 & \\
\hline safe & 2009 & 9.7483 & 2009 & 2011 & \\
\hline thoracic scoliosis & 2009 & 8.8558 & 2009 & 2012 & \\
\hline pelvic obliquity & 2009 & 8.7852 & 2009 & 2010 & \\
\hline thoracic insufficiency syndrome & 2009 & 8.4898 & 2009 & 2011 & \\
\hline segmental spinal instrumentation & 2009 & 7.842 & 2009 & 2013 & \\
\hline melatonin & 2009 & 7.0733 & 2009 & 2014 & \\
\hline intraobserver & 2009 & 6.6025 & 2009 & 2012 & \\
\hline spinal cord injury & 2009 & 6.5736 & 2009 & 2010 & \\
\hline expansion thoracoplasty & 2009 & 6.3349 & 2009 & 2011 & \\
\hline locus & 2009 & 6.2725 & 2009 & 2013 & \\
\hline rib cage & 2009 & 6.2404 & 2009 & 2014 & \\
\hline thoracic spine & 2009 & 7.3704 & 2010 & 2011 & \\
\hline boston brace & 2009 & 7.3495 & 2010 & 2013 & \\
\hline internal fixation & 2009 & 7.3047 & 2010 & 2012 & \\
\hline thoracic pedicle screw & 2009 & 7.0965 & 2010 & 2012 & \\
\hline excision & 2009 & 6.4028 & 2010 & 2012 & \\
\hline posterior instrumentation & 2009 & 9.1916 & 2011 & 2013 & \\
\hline assignment & 2009 & 7.5537 & 2011 & 2013 & \\
\hline thoracoplasty & 2009 & 6.7551 & 2012 & 2013 & \\
\hline transpsoas approach & 2009 & 6.2565 & 2013 & 2016 & \\
\hline survival & 2009 & 6.2932 & 2014 & 2015 & \\
\hline adult spinal deformity & 2009 & 24.624 & 2016 & 2018 & \\
\hline clinically important difference & 2009 & 6.4942 & 2016 & 2018 & \\
\hline spinal deformity surgery & 2009 & 6.2877 & 2016 & 2018 & \\
\hline
\end{tabular}

Figure 5 The top 25 terms with the strongest citation bursts during 2009 to 2018 . 

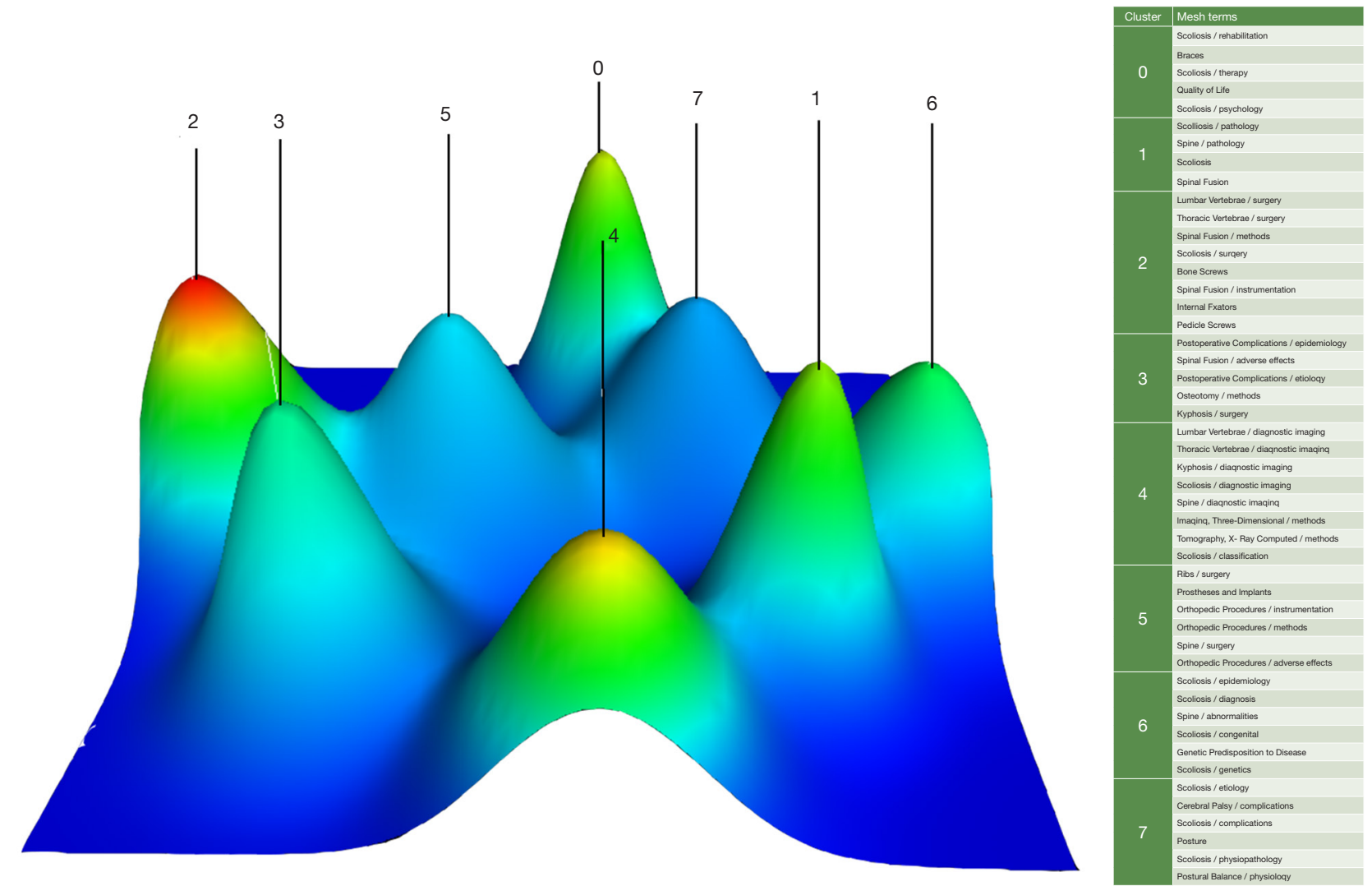

Figure 6 Mountain visualization of biclustering of highly frequent major MeSH terms and literatures on scoliosis. MeSH, Medical Subject Headings.

and location on the flat. The flat location can distinguish different perks and their interval represents their relative similarity of each cluster. The altitude and color of the perks are usually proportional to the internal similarity and standard deviation of the cluster (blue: high deviation; red: low deviation). The volume of peaks directly reflects the number of extremely frequent major MeSH terms/ $\mathrm{MeSH}$ subheadings in each cluster. In addition, every cluster should contain at least 30 publications and no triplet perks are allowed to emerge in mountain visualization. In matrix visualization, the column tags and row tags represent PMIDs of source literature and $\mathrm{MeSH}$ terms/MeSH subheadings, respectively. The matrix values are represented graphically and their colors paint the emergence frequency of the major $\mathrm{MeSH}$ terms/MeSH subheadings in a piece of literature. The color turns from white to red to show a gradual increase in significance (Figure 7). To make analogous rows in a single converged cluster, we reset the rows of the initial matrix and used black horizontal lines to partition each cluster through gCLUTO (Table 6). In matrix visualization, the upper cluster tree represented the literature association and the left cluster tree represented extremely frequent $\mathrm{MeSH}$ terms/subheadings association (Figure 7). The above-mentioned 52 extremely frequent terms were divided into 8 clusters and all representative source literature involved in each cluster was studied to summarize the hotspot information further. We finally generalized them into the following 8 hotspots:

(I) Quality of life and levels of psychological stress in patients with adolescent idiopathic scoliosis (AIS) treated with braces (Cluster 0 );

(II) Pathology of scoliosis (Cluster 1);

(III) Innovative instrumentation and methods used in the surgery of scoliosis (Cluster 2);

(IV) Adverse effects of scoliosis (Cluster 3);

(V) Diagnostic imaging of scoliosis (Cluster 4);

(VI) Prostheses and implants of scoliosis (Cluster 5);

(VII) Genetics researches of scoliosis (Cluster 6); 




Figure 7 Visualized matrix of biclustering of highly frequent major MeSH terms and PubMed Unique Identifiers (PMIDs) of literatures on scoliosis. MeSH, Medical Subject Headings.

Table 6 Highly frequent major MeSH a terms-source literatures matrix (localized)

\begin{tabular}{|c|c|c|c|c|c|c|}
\hline No. & Major MeSH terms/MeSH subheadings & \multicolumn{5}{|c|}{ PubMed Unique Identifiers of source articles } \\
\hline 1 & Scoliosis/surgery & 1 & 1 & 1 & $\ldots$ & 0 \\
\hline 2 & Spinal fusion/methods & 1 & 0 & 0 & $\ldots$ & 0 \\
\hline 3 & Scoliosis/diagnostic imaging & 0 & 0 & 0 & $\ldots$ & 1 \\
\hline$\cdots$ & $\cdots$ & $\cdots$ & $\cdots$ & $\cdots$ & $\cdots$ & $\cdots$ \\
\hline 47 & Scoliosis/classification & 0 & 0 & 0 & $\ldots$ & 0 \\
\hline 48 & Genetic predisposition to disease & 0 & 0 & 0 & $\ldots$ & 0 \\
\hline
\end{tabular}

MeSH, Medical Subject Headings.

(VIII) Asymmetrical postures in cerebral palsy (CP) resulting in scoliosis (Cluster 7).

\section{Discussion}

Our statistical and quantitative analysis found that the research output on scoliosis gradually increased in the 10 years from 2009 to 2018, and more and more scholars are focusing their research in the field. Although the research has been extensive, it is relatively messy, and there is a lack of analysis of research hotspots. In this work, we focused on the discussion and interpretation of the eight clusters obtained by co-word biclustering analysis to predict and direct future research trends.

Cluster 0 relates to the quality of life and levels of psychological stress in patients with AIS treated with braces. AIS has been the most common form of spinal deformity in adolescents. Patients with curves between $20^{\circ}$ and $40^{\circ} \mathrm{cobb}$ degrees do not need to undergo surgery, and conservative treatment may be a better choice. Although there are 
several conservative treatment options, only bracing has been proved to be effective in increasing the spine balance rate and in reducing hump amplitude to prevent the progression of AIS and subsequent surgical needs further. The brace treatment has become the first choice for clinical use of such patients, and the modified "P" Cheneau brace has become a remarkable success as a conservative treatment for AIS on the basis of the SRS/SOSORT criteria $(13,14)$. In addition, related quality of life assessments has drawn great attention from orthopedists all over the world. Recent research found that all teenagers may have some psychological stress in the early stages of wearing a brace, but as they adapt to their new image, this pressure may not impact their long-term quality of life $(15,16)$. Considering early psychological stress, we believe research in this field will provide an important reference for the improvement of the brace as a treatment in the future, and that it may maintain its popularity as an area for future study.

Cluster 1 relates to the pathology of scoliosis, which includes the pathological changes caused by spine deformity and vertebral body rotation, as well as updates on the rapid diagnostic method of imaging. Morphological characteristics and pathological changes to the spine have a great impact on idiopathic scoliosis clinical treatment. Doctors tried their best to detect and reconstruct the actual situation of the patient based on the imaging examination, which can accurately assess pathologies such as spine alignment and dyskinesia. Novel computational methods to evaluate vertebral segmental movement and multiple detection methods have been established, such as a multichannel transmit/receive phased array RF coil which can be used for in vivo spine imaging, thereby rendering high-resolution spine imaging a promising new application in IS clinical research (17-19). More and more valuable literature will appear in the near future focused on this topic.

Cluster 2 relates to the innovative instrumentation and methods used in scoliosis surgery. In recent years, with the rapid development of medical technology, doctors and patients are increasingly pursuing surgical treatments. At the same time, the focus of medical research in the new era has gradually shifted from basic research to translational research. For patients to achieve the best recovery with minimal harm, doctors and scientists have improved a variety of surgical methods and invented more convenient types of surgical equipment based on their years of experience and research (19-22). In this era of innovation and cooperation, medical-industrial integration and clinical translation medicine will surely become the most popular area for development in the future and maybe the most popular research topic in the next decade.

Cluster 3 relates to the adverse effects of scoliosis. Orthopedic surgery for spinal deformity is a difficult and high-risk surgical method in the orthopedic field. Postoperative complications often occur, especially nerve damage. With the application of new surgical methods for spinal deformity; however, more attention has been paid to the related complications of different surgical procedures (23-26). Although, with the continuous development of surgeons' abilities and modern medical technology, the incidence of complications of surgery for spinal deformity is declining. Therefore, the number of studies in this area may gradually decrease in the future, and more attention will perhaps be paid to some rare complications in the form of case reports.

Cluster 4 relates to the diagnostic imaging of scoliosis. Scoliosis is usually detected during a standard physical examination performed by a general practitioner or school nurse. Cobb Angle plays an important role in idiopathic scoliosis as a main diagnostic index. However, although measurements have been established, Cobb Angle measures a two-dimensional $(2 \mathrm{D})$ projection that is actually a $3 \mathrm{D}$ distortion, so using Cobb Angle alone is not a reliable way of assessing the deformity. Based on the fact that the etiology of $3 \mathrm{D}$ malformations and idiopathic scoliosis is unknown, recent studies have shown interest in obtaining additional measures to describe and quantify scoliosis (27-30). The establishment of these methods can help improve the accuracy of scoliosis diagnosis, help surgeons to understand the patient's deformity better and guide further treatment. With the continuous development of augmented reality (AR), virtual reality (VR), and mixed reality (MR) technology, more detailed imaging methods will appear, and there will be a definite and significant increase in this type of research.

Cluster 5 relates to prostheses and implants for scoliosis. Surgical treatment of scoliosis in older children is more straightforward and includes correction of spinal curvature, internal fixation, and spinal fusion. However, spinal fusion may not be the best option for young children with significant growth potential because it limits further longitudinal growth of the spine, thereby limiting the growth of the thoracic cavity and potentially inhibiting lung development, leading to respiratory dysfunction and, in some cases, premature death. To address these issues, "nonfusion" technologies have recently been implemented with 
varying degrees of success, and are attracting increasing levels of attention. Various techniques have been used, such as dual growing rods, Shilla procedure, VEPTR (Vertical Prosthetic Titanium Prosthetic Rib), vertebral stapling, and vertebral tethering, each with advantages and disadvantages (31-34). The emergence of new implants and surgical techniques has seen improved treatments for patients with different conditions that meet the requirements of modern precision medicine. There is reason to believe that research in this area has bright prospects.

Cluster 6 relates to the genetics researches of scoliosis. In recent years, some studies have suggested that genetic factors play an important role in the pathogenesis of scoliosis. They also show a high degree of genetic heterogeneity in autosomal dominant or multifactorial inheritance patterns with major genes. Many studies identified idiopathic scoliosis-susceptible genes (such as SH3GL1, GADD45B, and FGF22) and linked them to idiopathic scoliosis, but these genes are not relevant to all idiopathic scoliosis cases (35-38). There is no doubt that idiopathic scoliosis is a hereditary disease, so finding its related pathogenic genes is of great significance for the prevention or treatment of idiopathic scoliosis, and it must be a hot spot for future research.

Cluster 7 relates to asymmetrical postures in cerebral palsy resulting in scoliosis. Cerebral palsy is an immature, non-progressive lesion that causes movement and postural disorders in the brain. Although cerebral palsy is a static encephalopathy, the related musculoskeletal pathology is usually progressive. Many patients with cerebral palsy, especially those with spastic hemiplegia, have asymmetrical frontal spine (39). Many studies have shown that postural asymmetry is associated with scoliosis, dislocation of the hip, contracture of the hip and knee joint, and the inability to change position $(40,41)$. Therefore, postural problems play an important role in preventing cerebral palsy in children with motor dysfunction. The discussion surrounding this topic has been very lively in the past decade, but because of its limited perspective, it is difficult to predict whether its popularity will continue in future research.

Nonetheless, there may have been some limitations to our study. The databases update continuously, and we only selected the literature published from 2009 to 2018, excluding those published in 2019. Therefore, a discrepancy may exist between our bibliometric analysis and real publication conditions. In addition, the amount of scoliosis-related literature may increase rapidly with the breakthrough of future research.

\section{Conclusions}

We summarized the publication information of scoliosisrelated literature in the 10 years from 2009 to 2018, including country and institution of origin, authors, and publication journal. We then analyzed the research hotspots based on these publications and predicted future popular trends. Effective treatment of idiopathic scoliosis patients and improvements in quality of life will become the focus of scoliosis research, containing many aspects. Many previous studies have focused on the classification of scoliosis and the choice of corresponding treatment methods. Bracing and surgical treatment will help patients at different stages. In addition, the emergence of new surgical methods, new equipment and new implants using cutting-edge technology, the invention of more accurate image examination and diagnostic technology, and evaluation of postoperative complications management and quality of life all contribute to improving patient outcomes. Finally, research on the etiology of scoliosis, especially genetic research, has great potential to guide the prevention and treatment of scoliosis in the future. We believe our research can reflect novel directions for scoliosis research, and the hotspots mentioned will achieve major scientific breakthroughs someday.

\section{Acknowledgments}

Funding: None.

\section{Footnote}

Conflicts of Interest: The authors have no conflicts of interest to declare.

Ethical Statement: The authors are accountable for all aspects of the work in ensuring that questions related to the accuracy or integrity of any part of the work are appropriately investigated and resolved.

Open Access Statement: This is an Open Access article distributed in accordance with the Creative Commons Attribution-NonCommercial-NoDerivs 4.0 International License (CC BY-NC-ND 4.0), which permits the noncommercial replication and distribution of the article with the strict proviso that no changes or edits are made and the original work is properly cited (including links to both the formal publication through the relevant DOI and the license). See: https://creativecommons.org/licenses/by-nc-nd/4.0/. 


\section{References}

1. Yaman O, Dalbayrak S. Idiopathic scoliosis. Turk Neurosurg 2014;24:646-57.

2. Cheng JC, Castelein RM, Chu WC, et al. Adolescent idiopathic scoliosis. Nat Rev Dis Primers 2015;1:15030.

3. Gambín-Botella J, Ayala M, Alfonso-Beltrán J, et al. Predominance of Studies With Poor Level of Evidence Among the Top 100 Most Cited Studies on Idiopathic Scoliosis: A Bibliometric and Content Analysis. Spine deformity 2018;6:373-83.

4. Zhai X, Cui J, Shao J, et al. Global research trends in spinal ultrasound: a systematic bibliometric analysis. BMJ Open 2017;7:e015317.

5. Zhou S, Tao Z, Zhu Y, et al. Mapping theme trends and recognizing hot spots in postmenopausal osteoporosis research: a bibliometric analysis. PeerJ 2019;7:e8145.

6. Li F, Li M, Guan P, et al. Mapping publication trends and identifying hot spots of research on Internet health information seeking behavior: a quantitative and co-word biclustering analysis. J Med Internet Res 2015;17:e81.

7. Landis JR, Koch GG. The measurement of observer agreement for categorical data. Biometrics 1977;33:159-74.

8. Cui L Liu W Yan L, et al. Development of a text mining system based on the co-occurrence of bibliographic items in literature. New Technology of Library and Information Service 2008;8:70-5.

9. Eyre-Walker A, Stoletzki N. The assessment of science: the relative merits of post-publication review, the impact factor, and the number of citations. PLoS Biol 2013;11:e1001675.

10. Chen C. CiteSpace II: Detecting and visualizing emerging trends and transient patterns in scientific literature. J Am Soc Inf Sci 2006;57:359-77.

11. Chen C, Ibekwe-SanJuan F, Hou J. The structure and dynamics of cocitation clusters: A multiple-perspective cocitation analysis. J Am Soc Inf Sci 2010;61:1386-409.

12. K L. gCLUTO-Graphical Clustering Toolkit. 2014. Available online: http://glaros.dtc.umn.edu/gkhome/cluto/ gcluto/download

13. Pasquini G, Cecchi F, Bini C, et al. The outcome of a modified version of the Cheneau brace in adolescent idiopathic scoliosis (AIS) based on SRS and SOSORT criteria: a retrospective study. Eur J Phys Rehabil Med 2016;52:618-29.

14. Ersen O, Bilgic S, Koca K, et al. Difference between Spinecor brace and Thoracolumbosacral orthosis for deformity correction and quality of life in adolescent idiopathic scoliosis. Acta Orthop Belg 2016;82:710-4.

15. Kinel E, Kotwicki T, Podolska A, et al. Quality of life and stress level in adolescents with idiopathic scoliosis subjected to conservative treatment. Stud Health Technol Inform 2012;176:419-22.

16. Schwieger T, Campo S, Weinstein SL, et al. Body Image and Quality of Life and Brace Wear Adherence in Females With Adolescent Idiopathic Scoliosis. J Pediatr Orthop 2017;37:e519-23.

17. Shi B, Mao S, Xu L, et al. Factors favoring regain of the lost vertical spinal height through posterior spinal fusion in adolescent idiopathic scoliosis. Sci Rep 2016;6:29115.

18. Kraff O, Bitz AK, Kruszona S, et al. An eight-channel phased array $\mathrm{RF}$ coil for spine MR imaging at $7 \mathrm{~T}$. Invest Radiol 2009;44:734-40.

19. Wessels M, Homminga JJ, Hekman EE, et al. A novel anchoring system for use in a nonfusion scoliosis correction device. Spine J 2014;14:2740-7.

20. Imagama S, Ito Z, Wakao N, et al. Posterior Surgery for Adolescent Idiopathic Scoliosis With Pedicle Screws and Ultrahigh-Molecular Weight Polyethylene Tape: Achieving the Ideal Thoracic Kyphosis. Clin Spine Surg 2016;29:E376-83.

21. Huang Y, Feng G, Song Y, et al. Efficacy and safety of one-stage posterior hemivertebral resection for unbalanced multiple hemivertebrae: A more than 2-year follow-up. Clin Neurol Neurosurg 2017;160:130-6.

22. Kato S, Lewis SJ. Temporary Iliac Fixation to Salvage an Acute L4 Chance Fracture: Following Pedicle Screw Fixation for Adolescent Idiopathic Scoliosis. Spine (Phila Pa 1976) 2017;42:E313-6.

23. Lenke LG, Newton PO, Sucato DJ, et al. Complications after 147 consecutive vertebral column resections for severe pediatric spinal deformity: a multicenter analysis. Spine (Phila Pa 1976) 2013;38:119-32.

24. Bao H, He S, Liu Z, et al. Will immediate postoperative imbalance improve in patients with thoracolumbar/lumbar degenerative kyphoscoliosis? A comparison between Smith-Petersen osteotomy and pedicle subtraction osteotomy with an average 4 years of follow-up. Spine (Phila Pa 1976) 2015;40:E293-300.

25. Zhao H, Hu CF, Hai Y. Risk factors of postoperative major complication after spine deformity surgery. Zhonghua Yi Xue Za Zhi 2016;96:1815-7.

26. La Maida GA, Luceri F, Gallozzi F, et al. Complication rate in adult deformity surgical treatment: safety of the posterior osteotomies. Eur Spine J 2015;24 Suppl $7: 879-86$. 
27. Kawakami N, Tsuji T, Imagama S, et al. Classification of congenital scoliosis and kyphosis: a new approach to the three-dimensional classification for progressive vertebral anomalies requiring operative treatment. Spine (Phila $\mathrm{Pa}$ 1976) 2009;34:1756-65.

28. Forsberg D, Lundstrom C, Knutsson H. Eigenspine: computing the correlation between measures describing vertebral pose for patients with adolescent idiopathic scoliosis. Comput Med Imaging Graph 2014;38:549-57.

29. Thong W, Parent S, Wu J, et al. Three-dimensional morphology study of surgical adolescent idiopathic scoliosis patient from encoded geometric models. Eur Spine J 2016;25:3104-13.

30. Offiah A, Alman B, Cornier AS, et al. Pilot assessment of a radiologic classification system for segmentation defects of the vertebrae. Am J Med Genet A 2010;152A:1357-71.

31. Smith JT. Bilateral rib-to-pelvis technique for managing early-onset scoliosis. Clin Orthop Relat Res 2011;469:1349-55.

32. Hershman SH, Park JJ, Lonner BS. Fusionless surgery for scoliosis. Bull Hosp Jt Dis (2013) 2013;71:49-53.

33. LaGreca J, Flynn T, Cahill PJ, et al. Patients Without Intraoperative Neuromonitoring (IONM) Alerts During VEPTR Implantation Did Not Sustain Neurological Injury During Subsequent Routine Expansions: A Retrospective Multicenter Cohort Study. J Pediatr Orthop 2017;37:e619-24.

Cite this article as: Tao L, Zhou S, Tao Z, Wen K, Da W, Meng Y, Zhu Y. The publication trends and hot spots of scoliosis research from 2009 to 2018: a 10-year bibliometric analysis. Ann Transl Med 2020;8(6):365. doi: 10.21037/ atm.2020.02.67
34. Abol Oyoun N, Stuecker R. Bilateral rib-to-pelvis Eiffel Tower VEPTR construct for children with neuromuscular scoliosis: a preliminary report. Spine J 2014;14:1183-91.

35. Wu N, Ming X, Xiao J, et al. TBX6 null variants and a common hypomorphic allele in congenital scoliosis. $\mathrm{N}$ Engl J Med 2015;372:341-50.

36. Xu L, Xia C, Qin X, et al. Genetic variant of BNC2 gene is functionally associated with adolescent idiopathic scoliosis in Chinese population. Mol Genet Genomics 2017;292:789-94.

37. Yang T, Jia Q, Guo H, et al. Epidemiological survey of idiopathic scoliosis and sequence alignment analysis of multiple candidate genes. Int Orthop 2012;36:1307-14.

38. Gao W, Chen C, Zhou T, et al. Rare coding variants in MAPK7 predispose to adolescent idiopathic scoliosis. Hum Mutat 2017;38:1500-10.

39. Malak R, Gajewska E, Samborski W, et al. The shape of the spine among children with cerebral palsy. Chir Narzadow Ruchu Ortop Pol 2010;75:108-13.

40. Kawakami M, Liu M, Otsuka T, et al. Asymmetric skull deformity in children with cerebral palsy: frequency and correlation with postural abnormalities and deformities. J Rehabil Med 2013;45:149-53.

41. Rodby-Bousquet E, Czuba T, Hagglund G, et al. Postural asymmetries in young adults with cerebral palsy. Dev Med Child Neurol 2013;55:1009-15. 